\title{
APLIKASI PENGENALAN PAKAIAN ADAT MENGGUNAKAN AUGMENTED REALITY DENGAN METODE MARKERLESS
}

\author{
Diana $^{1}$, Agung Aji Nugraha ${ }^{2}$ \\ ${ }^{1,2}$ Fakultas Teknik, Informatika ,Universitas Muhamadiyah Bengkulu \\ J1. Bali Po.Box, 188 Kota Bengkulu 38119 \\ Telp. (0736) 22765 Fax. (0736) 26161 \\ e-mail : diana@umb.ac.id, elastico.1@outlook.com
}

\begin{abstract}
Bengkulu as one of the Provinces in Indonesia possesses a culture of traditional clothing and traditional musical instruments that must be preserved by the nation's next generation. The shortcoming of technology use in the preservation of traditional clothing and traditional musical instruments makes many juveniles unaware of information about traditional houses. One way to introduce traditional clothing and traditional musical instruments is to use Augmented Reality (AR) technology based on Android. This technology enables the users to see information, $3 D$ objects from $2 D$ objects, and sound directly. One method applied namely Augmented Reality. it is single marker, where one marker can only display one 3D object and cannot read more than one marker. This application can be utilized as distinct alternative to introduce traditional clothing and traditional Bengkulu musical instruments to the community both inside and outside Bengkulu Province.
\end{abstract}

Keywords - Augmented Reality, Traditional Clothing and Traditional Music Instrument, Single Marker, Android

\begin{abstract}
ABSTRAK
Bengkulu sebagai salah satu bagian Provinsi di Indonesia memiliki budaya berupa baju adat dan alat musik tradisional yang harus dilestarikan oleh para generasi penerus bangsa. Kurangnya penggunaan teknologi dalam pelestarian pakaian adat dan alat musik tradisional membuat generasi muda banyak yang tidak mengetahui infomasi mengenai rumah adat. Salah satu cara memperkenalkan pakaian adat dan alat musik tradisional yaitu menggunakan teknologi Augmented Reality (AR) yang berbasis Android. Teknologi ini memungkinkan para penggunanya melihat informasi, objek $3 D$ dari objek $2 D$, dan suara secara langsung. Salah satu metode yang digunakan Augmented Reality adalah single marker, dimana satu marker hanya dapat menampilkan satu objek $3 D$ dan tidak dapat membaca lebih dari satu marker. Aplikasi ini dapat digunakan sebagai alternatif lain untuk memperkenalkan pakaian adat dan alat musik tradisional Bengkulu kepada masyarakat baik di dalam maupun di luar Provinsi Bengkulu.
\end{abstract}

Kata Kunci-Augmented Reality, Pakaian Adat, Alat Musik, Single Marker, Android 


\section{Pendahuluan}

Indonesia memiliki kekayaan yang sangat luar biasa, mulai dari kekayaan alam dan budaya. Pakaian adat merupakan salah satu dari banyak kekayaan yang dimiliki oleh Indonesia, yang mana kebudayaan tersebut harus dilestarikan oleh para generasi penerus bangsa.

Pakaian adat mencirikan suatu daerah yang melambangkan kebudayaan dan ciri khas masyarakat setempat ${ }^{[15]}$. Hingga saat ini masih banyak suku atau daerah-daerah di Indonesia yang masih memperhatikan pakaian adat dan sebagai usaha untuk memelihara nilai-nilai budaya.

Bengkulu sebagai salah satu bagian Provinsi di Indonesia juga memiliki budaya berupa baju adat yang harus dilestarikan oleh para generasi penerus bangsa. Kurangnya penggunaan teknologi dalam pelestarian pakaian adat membuat generasi muda banyak yang tidak mengetahui infomasi mengenai rumah adat.

Salah satu cara memperkenalkan pakaian adat yaitu menggunakan teknologi Augmented Reality (AR) yang berbasis Android. Teknologi ini memungkinkan para penggunanya melihat informasi, objek 3D dari objek 2D, dan suara secara langsung.

Augmented Reality adalah teknologi yang menggabungkan obyek-obyek maya yang ada dan dihasilkan (generated) oleh komputer dengan benda-benda yang ada di dunia nyata sekitar kita, dan dalam waktu yang nyata. Tidak seperti realitas maya yang sepenuhnya menggantikan kenyataan, Augmented Reality hanya melengkapi kenyataan ${ }^{[1]}$.

Salah satu metode Augmented Reality yang saat ini sedang berkembang adalah metode Markerless Augmented Reality, dengan metode ini pengguna tidak perlu lagi menggunakan sebuah user defined target untuk menampilkan elemen-elemen digital $^{[2]}$. Dalam perancangannya, seolaholah markerless menggabungkan objek virtual dengan objek nyata, dalam hal ini objek virtual berupa objek 2D atau 3D dan objek nyatanya berupa gambar dengan pola tertentu (markerless).

\section{Metode Penelitian}

A. Model Pengemabangan Sistem

Model pengembangan sistem yang akan digunakan dalam penelitian ini adalah model Rapid Application Development (RAD). RAD adalah model proses pembangunan perangkat lunak yang incremental. RAD menekankan pada siklus pembangunan yang pendek/ singkat. RAD mengadopsi model waterfall dan pembangunan dalam waktu singkat dicapai dengan menerapkan component based construction $^{[3]}$. 
Sistem dibagi-bagi menjadi beberapa modul dan dikerjakan dalam waktu yang hampir bersamaan dalam batas waktu yang sudah ditentukan.

1. Business modeling berkaitan dengan analisis kebutuhan sistem untuk menampilan 3D dari Pakian Adat.

2. Data modeling berkaitan dengan analisis kebutuhan data. Pengumpulan data diperlukan untuk pengenalan Tabot. Pengumpulan data tersebut akan diperoleh dari dokumentasi, studi pustaka dan observasi.

3. Process modeling dengan menggunakan Unified Modelling Language (UML).
4. Application generation pada aplikasi ini adalah dengan menggambarkan sistem baru yang akan dikembangkan secara logis tanpa mempertimbangkan terlebih dahulu lingkungan sistem.

5. Testing and turnover dilakukan untuk mendapatkan penilaian langsung terhadap sistem yang dihasilkan.

\section{Tim\#1}

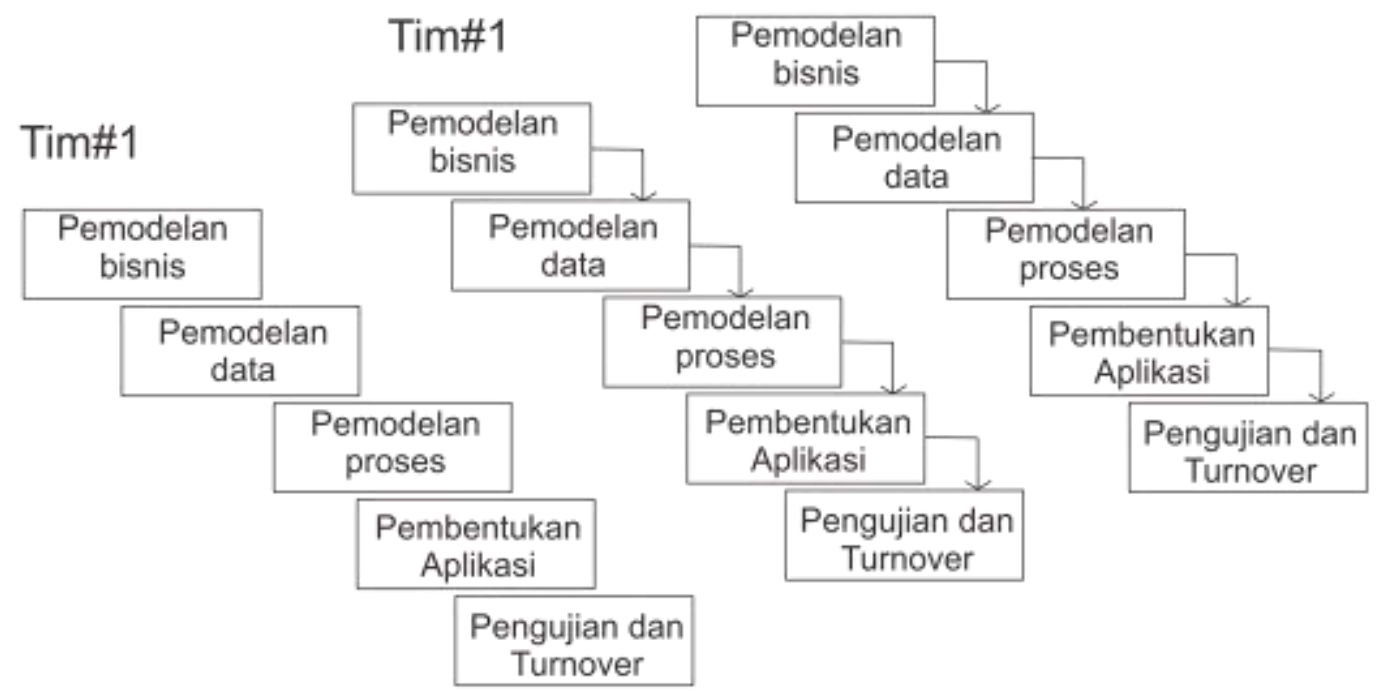

\section{0-90hari}

\section{Gambar 1. Fase RAD}

B. Perancangan Aplikasi
Perancangan aplikasi meliputi proses perancangan navigasi dan perancangan 
tampilan dari aplikasi. Pada aplikasi pengenalan pakaian adat Kota Bengkulu menggunakan teknologi augmented reality berbasis Android, terdapat proses-proses yang dapat diimplementasikan, yaitu:

a. Sistem dapat menampilkan pakaian adat Kota Bengkulu dalam bentuk 3D yang dapat digerakkan secara rotasi sesuai keinginan user.

b. Secara umum perangkat lunak ini menggunakan kamera sebagai media pendukung penggunaan aplikasi ini.

C. Desain Aplikasi

Struktur menu Aplikasi Pengenalan Tabot menggunakan teknologi augmented reality berbasis Android terdiri dari 4 menu, yaitu AR, Informasi, Panduan dan Keluar.

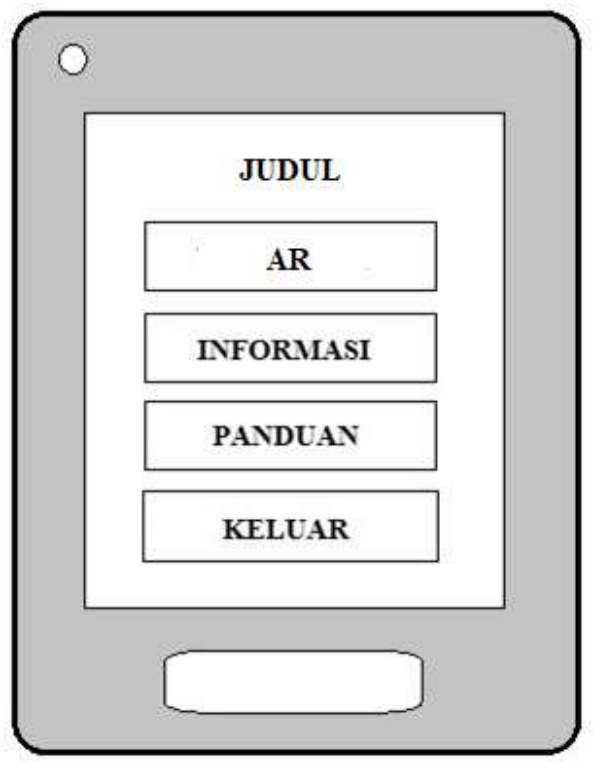

Gambar 2. Rancangan Tampilan Menu Utama Aplikasi
1. Rancangan Menu AR

Menu AR digunakan untuk melihat gambar 3D dari pakaian adat Kota Bengkulu. Jika Menu AR dipilih, maka otomatis terhubung dengan kamera handphone. Kamera handphone yang telah hidup kita letakkan di atas marker AR yang telah dibuat sehingga muncul gambar 3D dari pakaian adat Kota Bengkulu tersebut.

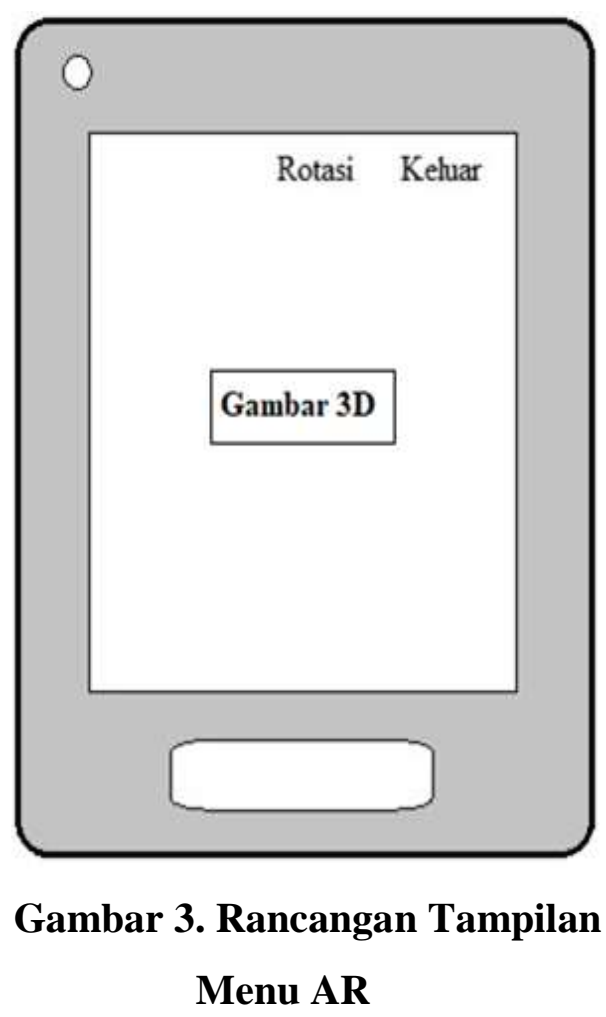

2. Rancangan Menu Informasi

Menu Informasi berisi tentang informasi lengkap mengenai pakaian adat Kota Bengkulu. 


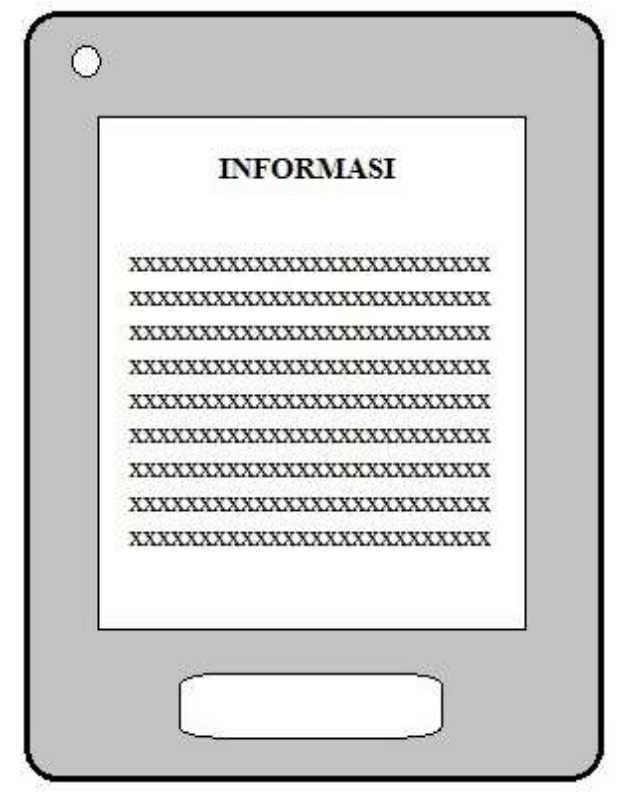

Gambar 4. Rancangan Tampilan

Menu Informasi

3. Rancangan Menu Panduan

Menu Panduan digunakan untuk bantuan kepada user dalam menggunakan aplikasi. Berikut adalah rancangan tampilan Menu Panduan.

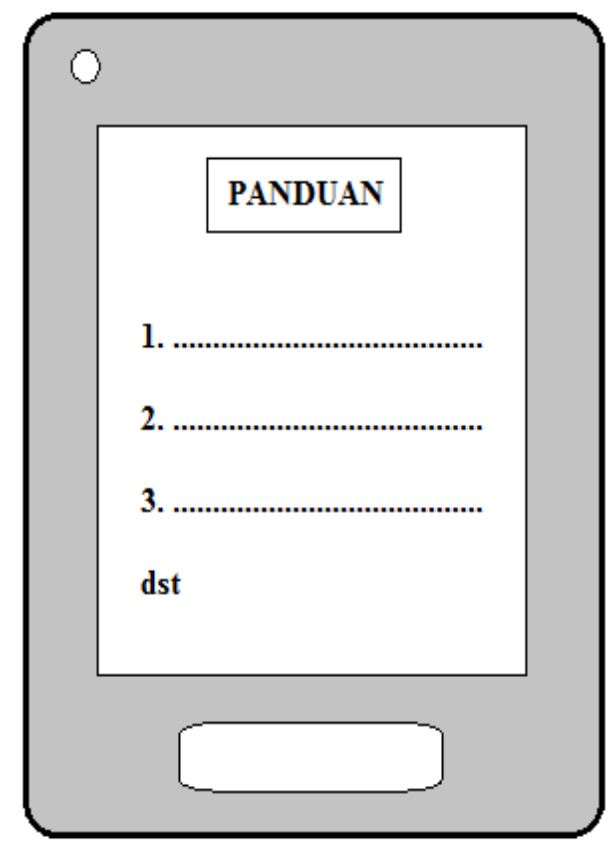

Gambar 5. Rancangan Tampilan Menu Panduan

\section{Rancangan Menu Keluar}

Menu Keluar digunakan untuk keluar dari aplikasi pengenalan pakaian adat Kota Bengkulu.

Metode Penelitian meliputi analisis, arsitektur, metode yang dipakai untuk menyelesaikan masalah, dan implementasi. Pada setiap paragraph bisa terdiri dari beberapa subparagraph yang dituliskan dengan penomoran angka arab seperti yang ditunjukkan section berikut ini.

\section{Hasil dan Pembahasan}

\section{A. Pembuatan Objek 3D}

Pembuatan Objek 3D Furniture Interior terdiri dari beberapa tahap, yaitu:

1. Tahap Modelling

Modeling (pembuatan 3 dimensi) Pakaian Adat dilakukan menggunakan Software Blender. Tahapan ini dilakukan dengan Import gambar Pakian Adat ke Blender kemudian di desain menjadi objek 3D.

\section{Tahap Texturing}

Proses Texturing ini menggunkan Software Blender dan Photoshop. Dimana Blender menentukan map-map Texture Difuse dan Photoshop berperan lebih Detailing.

\section{Tahap Exporting}

Setelah tahap texturing selesai, model yang selesai dibuat di export kedalam 
format.$f b x$ untuk dapat di Export ke Unity.

B. Pengujian Aplikasi

1. Tapilan Aplikasi Pakian Adat

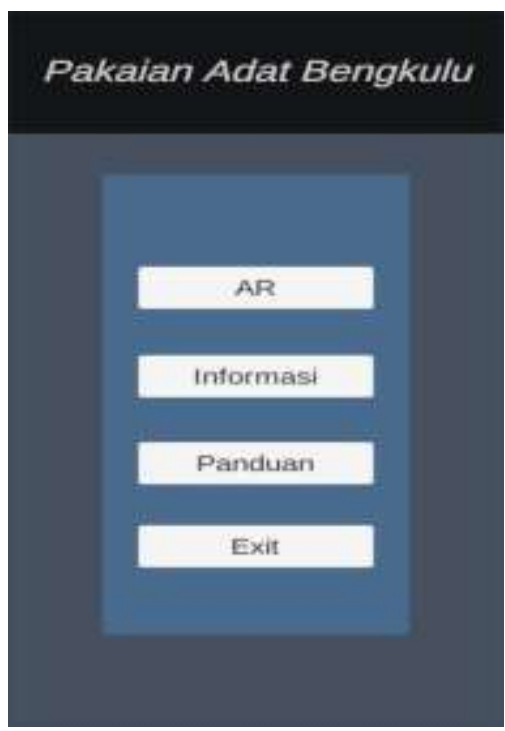

2. Tampilan Menu Informasi
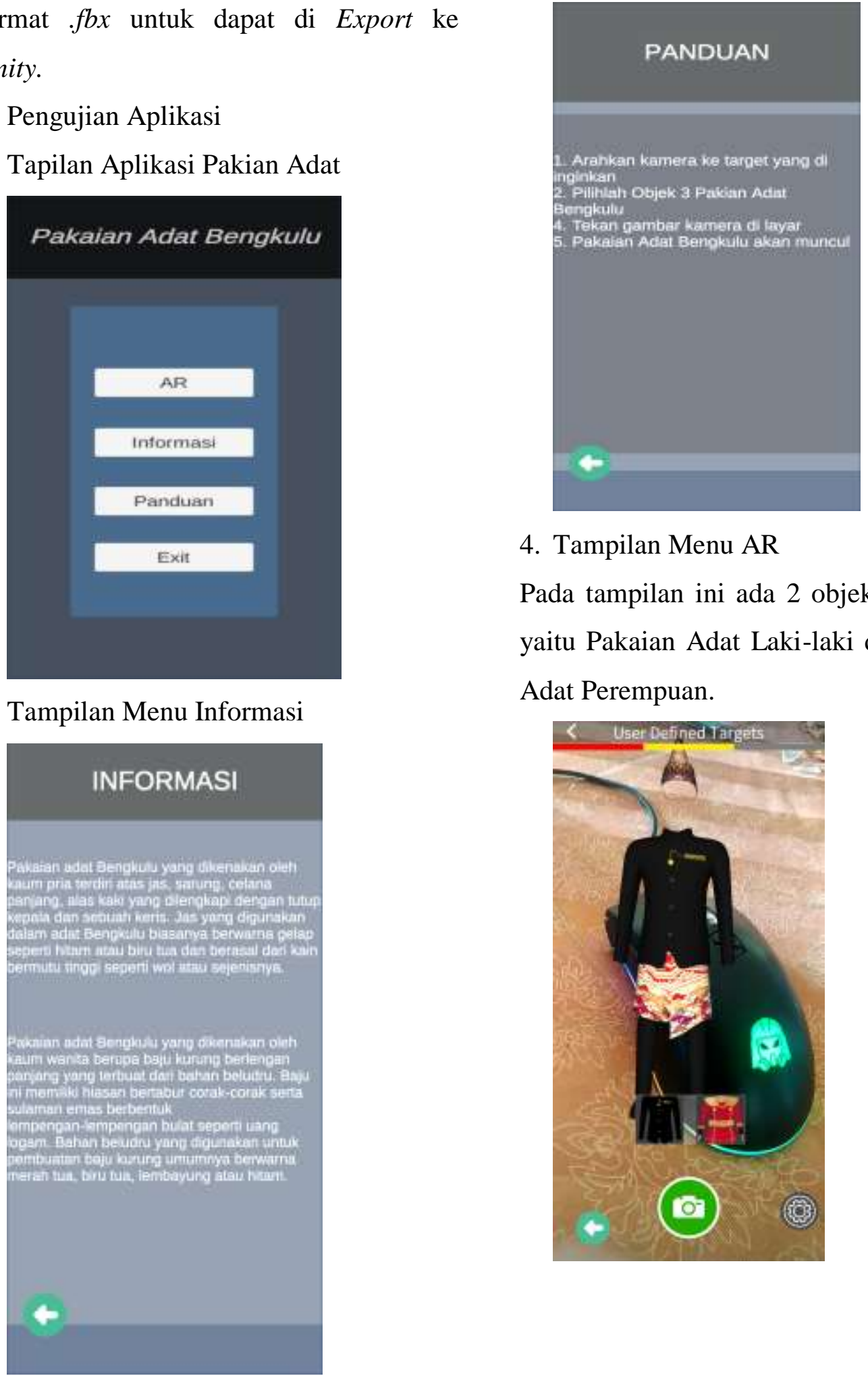

4. Tampilan Menu AR

Pada tampilan ini ada 2 objek 3 demensi yaitu Pakaian Adat Laki-laki dan Pakaian Adat Perempuan.

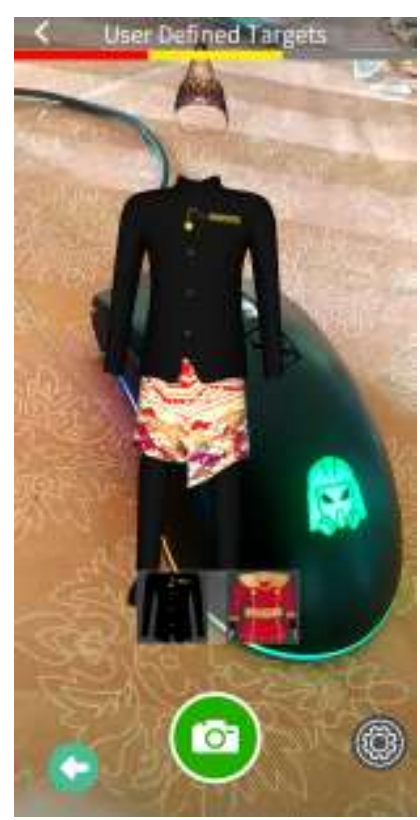

3. Tampilan Menu Panduan 


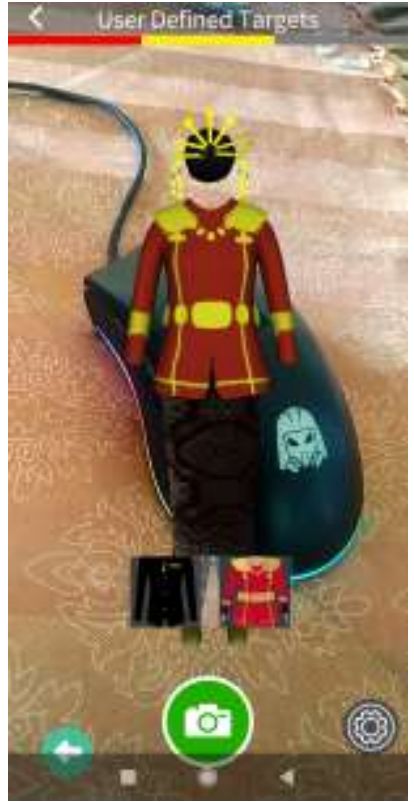

C. Tabel Pengujian

Pengujian ini dalakukan dengan menggunakan medote Black

Box,.Pengujian terdiri dari dua jenis uji yaitu pengujian terhadap jarak dan pengujian terhadap fungsi yang terdapat pada aplikasi.

\section{Tabel 1 Pengujian Jarak Kamera}

Bergerak Mundur dari Target

\begin{tabular}{|l|l|l|l|}
\hline NO & $\begin{array}{l}\text { Jarak } \\
(\mathbf{c m})\end{array}$ & $\begin{array}{l}\text { Hasil yang } \\
\text { diharapkan }\end{array}$ & $\begin{array}{l}\text { Tingkat } \\
\text { Keberhasilan }\end{array}$ \\
\hline 1 & $50 \mathrm{~cm}$ & $\begin{array}{l}\text { Dapat melakukan } \\
\text { jarak tracking } 50 \mathrm{~cm}\end{array}$ & Berhasil \\
\hline 2 & $100 \mathrm{~cm}$ & $\begin{array}{l}\text { Dapat melakukan } \\
\text { jarak tracking 100cm }\end{array}$ & Berhasil \\
\hline 3 & $150 \mathrm{~cm}$ & $\begin{array}{l}\text { Dapat melakukan } \\
\text { jarak tracking 150cm }\end{array}$ & Berhasil \\
\hline 4 & $\begin{array}{l}\text { Dapat melakukan } \\
\text { jarak tracking } \\
\text { 200cm(objek } \\
\text { bergerak-gerak) }\end{array}$ & $\begin{array}{l}\text { Tidak } \\
\text { Berhasil }\end{array}$ \\
\hline 5 & $300 \mathrm{~cm}$ & $\begin{array}{l}\text { Dapat melakukan } \\
\text { jarak tracking 300cm } \\
\text { (objek bergerak-gerak } \\
\text { dan hilang) }\end{array}$ & $\begin{array}{l}\text { Tidak } \\
\text { Berhasil }\end{array}$ \\
\hline $7300 \mathrm{c}$ & $\begin{array}{l}\text { Dapat melakukan } \\
\text { jarak tracking lebih } \\
\text { dari 300cm (objek } \\
\text { bergerak-gerak g dan } \\
\text { hilang) }\end{array}$ & $\begin{array}{l}\text { Tidak } \\
\text { Berhasil }\end{array}$ \\
\hline
\end{tabular}

Tabel 2 Pengujian Terhadap Itensitas Cahaya Lampu LED

\begin{tabular}{|l|l|l|l|}
\hline NO & $\begin{array}{l}\text { Cahaya } \\
\text { Lampu } \\
\text { LED }\end{array}$ & $\begin{array}{l}\text { Hasil Yang } \\
\text { Diharapkan }\end{array}$ & $\begin{array}{l}\text { Tingkat } \\
\text { Keberh } \\
\text { asilan }\end{array}$ \\
\hline $\mathbf{1}$ & $\begin{array}{l}\text { Lampu 5 } \\
\text { watt }\end{array}$ & $\begin{array}{l}\text { Dapat Melakukan } \\
\text { Tracking }\end{array}$ & $\begin{array}{l}\text { Tidak } \\
\text { Berhasil }\end{array}$ \\
\hline $\mathbf{2}$ & $\begin{array}{l}\text { Lampu 10 } \\
\text { watt }\end{array}$ & $\begin{array}{l}\text { Dapat Melakukan } \\
\text { Tracking }\end{array}$ & Berhasil \\
\hline $\mathbf{3}$ & $\begin{array}{l}\text { Lampu 15 } \\
\text { watt }\end{array}$ & $\begin{array}{l}\text { Dapat Melakukan } \\
\text { Tracking }\end{array}$ & Berhasil \\
\hline $\mathbf{4}$ & $\begin{array}{l}\text { Lampu 20 } \\
\text { watt }\end{array}$ & $\begin{array}{l}\text { Dapat Melakukan } \\
\text { Tracking }\end{array}$ & Berhasil \\
\hline
\end{tabular}

Tabel 3 Pengujian Terhadap Itensitas Cahaya Matahari

\begin{tabular}{|l|l|l|l|}
\hline NO & $\begin{array}{l}\text { Cahaya Lampu } \\
\text { Matahari }\end{array}$ & $\begin{array}{l}\text { Hasil Yang } \\
\text { Diharapkan }\end{array}$ & $\begin{array}{l}\text { Tingkat } \\
\text { Keberh } \\
\text { asilan }\end{array}$ \\
\hline $\mathbf{1}$ & $\begin{array}{l}\text { Cahaya Matahari } \\
\text { Outdoor }\end{array}$ & $\begin{array}{l}\text { Dapat } \\
\text { Melakukan } \\
\text { Tracking }\end{array}$ & Berhasil \\
\hline $\mathbf{2}$ & $\begin{array}{l}\text { Cahaya Matahari } \\
\text { Indoor }\end{array}$ & $\begin{array}{l}\text { Dapat } \\
\text { Melakukan } \\
\text { Tracking }\end{array}$ & Berhasil \\
\hline
\end{tabular}

Pembahasan terhadap hasil penelitian dan pengujian yang diperoleh disajikan dalam bentuk uraian teoritik, baik secara kualitatif maupun kuantitatif. Hasil percobaan sebaiknya ditampilkan dalam berupa grafik ataupun tabel. Untuk grafik dapat mengikuti format untuk diagram dan gambar.

\section{Simpulan}

Dari penelitian yang telah dilakukan, didapatkan beberapa kesimpulan antara lain:

1. Objek tiga dimensi dapat divisualisasikan dalam perangkat handphone saat pengguna menentukan target. 
2. Jarak pada saat proses tracking ke marker sangat mempengaruhi muncul tidaknya sebuah objek 3D. Jarak yang diperlukan agar target terdeteksi oleh sistem adalah kurang dari 50-100 cm.

3. Semakin bagus intensitas cahaya yang didapatkan maka sistem akan semakin cepat dalam mengenali target dan sebaliknya ketika tidak terdapat cahaya maka sistem tidak dapat mendeteksi target.

\section{DAFTAR PUSTAKA}

[1] Haryani P dan Triyono J. 2017. Augmented Reality Sebagai Teknologi Interaktif Dalam Pengenalan Benda Cagar Budaya Kepada Masyarakat. Jurnal Simetris Vol 8 No 2 : 807-812.

[2] Laksono, G, \& Eko F.R. 2014. Pemanfaatan Teknologi Augmented Reality Markerless Sebagai Media Pengenalan Gedung Universitas Kanjuruhan Malang. Jurnal Penelitian. Malang: Unikama.

[3] Wahyuningrum, T, \& Dwi J. 2014 Perancangan web e-commerce dengan metode Rapid Application Development (RAD) untuk produk unggulan desa. diterbitkan. Dian Nuswantoro University.

[4] Andriyadi A. 2011. Augmented Reality With ARToolkit Reality
Leaves a lot to Imagine. Lampung. Augmented Reality Team.

[5] Fitria, S. Y., \& SeptiliaArfida, H. Green Cloud Computing Ideas with Security Issues in Setting of Distributed Computing and Cloud Framework.

[5] Ardhianto E, Hadikurniawati W,

Winarno E. 2012. Augmented Reality Objek 3 Dimensi dengan Perangkat ARToolKit dan Blender. Jurnal Teknologi Informasi Dinamik Volume 17 No 2: 107-117.

[6] Azuma RT. 1997. A survey of Augmented Reality. In Presence: Teleoperators and Virtual Environment 6: 355-385.

[7] Cholifah C, Ardilla F dan Hakkum RY. 2010. Rubber Ball - Virtual Game dengan menggunakan ARToolkit (Augmented Reality Toolkit).

[8] Desy. 2017. MonsterAR: Mengenal Jenis-Jenis dari Teknologi Augmented

Reality?.https://monsterar.net/2017/ 08/08/mengenal-jenis-augmentedreality/. Diakses tanggal 8 Juli 2019

[9] Edi W. 2011. Membuat Sendiri Aplikasi Android Untuk Pemula. Jakarta. Elexmedia Komputindo.

[10] Furht B. 2011. Handbook of Augmented Reality. Florida: 
Department of Computer and

Electrical Engineering and

Computer Science.

[11] Haryani P dan Triyono J. 2017. Augmented Reality Sebagai

Teknologi Interaktif Dalam Pengenalan Benda Cagar Budaya Kepada Masyarakat. Jurnal Simetris Vol 8 No $2: 807-812$.

[12] Jogiyanto. 2005. Sistem Informasi: Pendekatan Terstruktur Teori dan Prakik Aplikasi Bisnis. Andi Offset. Yogyakarta.

[13] Rahman GR dan Thalib F. 2011. Pengembangan Teknologi Augmented Reality sebagai Penunjang Industri Musik Indonesia.

[14] Remondino AM. 2012. A review of Reality-Based 3D Model Generation, Segmentation and WebBassed Visualization Methods.

[15] Tim Penulis. 2009. Mengenal Rumah Adat, Pakaian Adat, Tarian Adat danSenjata Tradisional 33 Provinsi di Indonesia. Jakarta: Penebar Cif

[16] Rifa'I M, Listyorini T, Latubessy A. 2014. Penerapan Teknologi Augmented Reality Pada Aplikasi Katalog Rumah Berbasis Android. Prosiding SNATIF ke-1:267-274. 